\title{
Managing Divided Loyalties in the Emerging Profession of Community Engagement
}

\begin{abstract}
Community engagement practitioners design, deliver, report and evaluate processes which invite the community to influence decision-making. It is a unique role, with practitioners serving two masters: the organisations that employ or contract them and the communities whose views they are engaged to elicit. In balancing these interests, practitioners experience a number of tensions in their work, and employ a variety of methods to address them. This paper draws on a series of 20 semi-structured interviews with senior practitioners, in an attempt to answer these questions and finds that a multiplicity of tensions exist which relate to the need to serve both the community and the engagement sponsor, their position in either the public sector or as a private consultants to the public sector and the constraints and behaviours of public institutions. They way in which they manage these is relatively ad-hoc, although is often informed by principals and position.
\end{abstract}

Key words: public participation; community engagement; professionalisation; tensions; practitioners; professionals

\section{Introduction}

It stands to reason that between Australia's multitude of public institutions - over 500 local governments as well as the departments and agencies of its federal government and those of its six states and two mainland territories - that there are a multitude of community consultation and engagement processes being undertaken. The use of these processes by public institutions for decision-making has become commonplace in recent years (Baiocchi and Ganuza, 2017; Bua and Escobar, 2018; Fung, 2015), not only in Australia (Grant and Drew 2017), but internationally (Baiocchi and Ganuza, 2017; Bherer et al., 2016; Lowndes et al., 2001; Michels and De Graaf, 2010; Nabatchi and Amsler, 2014; Nabatchi and Leighninger, 2015; Pateman, 2012; Wampler, 2010; Wang, 2001).

These processes are designed, coordinated, facilitated, evaluated, and managed by publicsector employees, not-for-profit employees, private sector employees and consultants, whom selfidentify as having the required skills to undertake these tasks. Such practitioners are a relatively recent phenomenon (Christensen 2018a). The roots of this emerging profession are often attributed to community activism (Aulich 2009) but the commercial engagement of practitioners on behalf of public institutions to run community engagement processes has only been seen in its current form in 
the last 30 years (Hendriks and Carson, 2008; Lee, 2015, 2017).

The work of these practitioners does not confirm to standard arrangements of service. Freidson (1989) highlighted that professional work differs and the markets it operates in differ: '[S]ome professions command bodies of knowledge and skill that serve the needs of individual clients while others serve the needs of institutions, organisations or aggregates of individuals' (Freidson, 1989: 429). In the case of community engagement practitioners, the knowledge and skills are simultaneously serving the needs of a client or employer which is an institution or organisation while at the same time serving the 'aggregates of individuals', understood to be the community and other stakeholders. Both parties must be satisfactorily 'attended to' (Moore 1995, p. 118) lest practitioners risk losing their income and livelihoods and/or the democratic process they are managing are viewed as a sham by communities and stakeholders. This is the case for practitioners who are employed in or, alternatively, contracted by public institutions - the focus of this research (henceforth public practitioners and consultant practitioners). In managing these divided loyalties, practitioners face a multitude of tensions.

It builds on previous studies (Bherer et al., 2017a, 2017b; Cooper and Smith, 2012; Chilvers, 2017; Escobar, 2017; Hendriks and Carson, 2008; Lee, 2014, 2015, 2017; Lewanski and Ravazzi, 2017; Mazeaud and Nonjon, 2017) but is unique, as it is the first to focus on the tensions that practitioners experience. By identifying these tensions, a more complete picture of the role of the practitioner and their influence on democratic processes can be understood. The research undertaken here focuses on Australian public practitioners and consultant practitioners working on behalf of public institutions . In this context, the practitioners are commonly known as community engagement 'practitioners'. However, members of this group have also been referred to as public participation professionals (PPPs) (Bherer et al., 2017b), public participation practitioners (Cooper and Smith, 2012), deliberation professionals (Lee, 2015), deliberative practitioners (Hendriks and Carson, 2008), public engagement professionals (Lee, 2015), public engagement consultants (Lee, 2014), and 
other similar terms.

To explore these tensions and how practitioners manage them the paper is arranged in six parts. First is a brief review of relevant literature as it pertains to practitioners and professional tensions is conducted. Second, an overview of the research methodology is provided. The third section explores the common tensions identified by those interviewed. These tensions have been themed into four areas: those that arise from loyalties divided; those that arise from being a public sector practitioner; those that spring from the constraints and behaviours of public institutions; and those that come from the community. The fourth section explores how practitioners manage these tensions and the final sections consider the findings, how they relate to existing theory and how they can assist in future development of the practice.

\section{Literature on Practitioners}

Increasing attention has been given to practitioners in recent years and two relevant themes can be identified. First, how practitioners negotiate the balance between commercial and community interest. One of the most significant contributions in this area is Hendriks and Carson (2008), who, after discussing the supply and demand of the deliberative market track the growth of deliberative consultants in Australia and conclude that consultants are more akin to a 'community of practice' than a marketplace. This is a position Cooper and Smith (2012) agree with. Lee $(2014 ; 2015 ; 2017)$ is more critical, concluding that practitioners balance 'democratizing' and 'bureaucratizing' logics by being both entrepreneurial and projecting the 'right' identities (Lee, 2014). Lee (2015) also explores the expansive network of economic drivers for professional engagement, such as commodification and concludes (Lee 2017) the focus on professionalisation may have come at the cost of actually addressing the democratic deficit. Bherer et al. (2017b) who explore the issue of impartiality in the context of commercialisation, conclude that practitioners can be defined by four professional identities based on the level of commitment they have to impartiality and commercial 
support for the project: promoter, reformer, militant and facilitator.

The second theme in the literature examines how practitioners are often constrained by the nature of public institutions. In their account of practitioners in Britian and Germany, Cooper and Smith (2012) argue that the 'structure and culture of public authorities' often hinders the effectiveness of participation as authorities fail to understand what is involved in engagement processes. Using an Italian case study, Lewanski and Revazzi (2017) discuss how the use of institutional frameworks, designed to promote and regulate practice, can affect practice, such as the standardisation of approach. Mazeaud and Nonjon (2017) report a similar situation in France, which they assert has led to a fracturing of the market. Meanwhile, Chilvers (2017) presents evidence from the United Kingdom that while public participation was designed to overcome technocratic practices, professionalisation has led to engagement becoming technocratic and institutionalised. Also the in the United Kingdom, is Escobar's (2017) study of practitioners employed by public institutions. Escobar discusses how these practitioners have additional challenges to face because of the political environment they are situated in.

\section{Literature on Professional Tensions}

There is also relevant scholarship which has examined the tensions in professional practice writ large. These include how market mechanisms adversely affect professional practice. For instance: Fawcett and Hanlon (2009) study human service workers in an environment of New Public Management (NPM); Gardner et al. (2001) compare journalists and genetic scientists in the face of technological innovation; Sawyer et al. (2009) researches nurses in the NPM context. All conclude that thte market adversely impacts upon professional practice in these diverse settings. Also evident in this broader literature is a concern with how the nature of public institutions can adversely affect practice: for example, Glennie et al. (2018) study government scientists and Lewis et al. (2003) examines General Practitioners in their quest for autonomy. This broader research suggests that the 
challenges of community engagement are not unique.

\section{Methodology}

This paper draws on the themes that relate to the tensions that practitioners face and how they manage them. In order to reflect on changes and trends in the practice, senior practitioners, defined as those with more than 10 years' experience, were targeted, creating a purposeful sample. The disadvantage of focusing on experienced practitioners means that this study does not identify how less experienced practitioners perceive and manage tensions. Of those selected, efforts were made to ensure there were a mix of public sector employees and private consultants to the public sector, genders and locations. Efforts were also made to seek participants who had differing views so that a degree of data saturation was achieved (Glaser and Strauss, 1967).

A total of 20 semi-structured interviews were conducted between November 2018 and January 2019 (see the Appendix for details). Interviewees were located in Australia's six states and were conducted in person or via video conference (Zoom) and ranged from 60 to 90 minutes. Participants were provided with draft questions before the interview and an information sheet explaining the study in more detail. The interviews were audio recorded and then transcribed. After the interviews, Dedoose was used to collate and code the transcripts in order to explore themes.

The findings in this paper present data from the survey and the qualitative responses were drawn primarily from three interview questions, namely: What is making it difficult/challenging to deliver good engagement? What types of tensions or dilemmas do you face in your work? How do you manage these?

\section{Tensions}

The origins of practitioner tensions emerged as four-fold. First, participants underscored that they experienced tensions from having the employer or client on one side and the community on the 
other. Second, whether their role was based inside a public institution, making them a public practitioner, or whether they work for a private company, making them a consultant practitioner. Third, participants identified constraints and behaviours of public institutions that often reside outside the control of practitioners but were often at odds with the processes and principles of community engagement. Fourth, participants, somewhat indirectly, identified tensions that arise from their work with the community itself.

\section{Employer vs Community}

The most pronounced source of internal and external tension for community engagement practitioners was reported as residing in the divided loyalties practitioners are expected to simultaneously attend to. Participants were earnest in their efforts to deliver meaningful engagement processes while satisfying the needs of their employer or client as well as the communities they were consulting. At the same time many, although not all, indicated a desire to do this, while at the same appearing loyal to neither party, placing the engagement process or the project as paramount (see Polletta, 2015). Practitioners were adept at describing this conundrum:

You are almost in between that rock and a hard place ...you are being paid by an organisation to get a community's view to influence the decision. So, on the one hand you want to do best by the community but occasionally there's that niggling voice at the back of your head telling you not to upset your employer and to toe the line.

A similar sentiment was evident with consultant practitioners, with one participant saying '[the tension] is absolutely the serving the two people: the client that pays your contract as a consultant as a consultant you want to do a good job because you want their business - but equally you've got to be true to the community'.

Whose side are you on anyway?

While the loyalties were commonly identified as residing in both client and community, so too were 
the risks if a careful balance between the two was not achieved, as one public practitioner described: 'personal integrity is a dilemma that they [practitioners] face. Their personal safety inside an organisation, their ongoing employment and even more broadly their reputation as a provider of good advice'. The advice that practitioners were dispensing was generally to organisations - be they the employer or client. It included advice on community engagement policy and strategy - such as defining the parameters of a community, the development of questions to ask the community, identification of suitable methods for engaging, and interpreting community sentiment and feedback. Some participants recounted that when they offered this advice they were frequently perceived as working against the greater aims of the organisation or the project. Conversely, some practitioners spoke of how communities could be suspicious of a practitioner's motives, assuming them to be aligned with the organisation who has engaged or paid them. As one practitioner described it, 'The toughest thing is that everybody thinks you're on the other side... and the worst thing is when it's your own work colleagues and you're just innocently giving the perspective [of the community].'

\section{Independent from?}

It is widely acknowledged in the international literature (Mansbridge et al., 2006; Moore, 2012; Spada and Vreeland, 2013) that when playing the intermediary between public institutions and the community practitioners see neutrality or impartiality as necessary to maintain integrity. The conversations with practitioners in this study differed in two ways. First, there was a tendency to use the term 'independent' rather than 'neutral' or 'impartial'. Second, it was often unclear which party they were seeking independence from. The desired goal was viewed as either independence from the either the employing organisation or independence from the project/subject matter under consideration. In speaking about how to demonstrate independence from the organisation, one participant stated:

I often say if they [the community] trust us [the practitioners] we can help them trust you [the 
organisation]. But if they're to trust us we are going to question you [the organisation] publicly. We are going to go with them on some things and then we can question them and go with ...you need to prove yourself to be independent.

Independence from the subject matter was viewed as a defining feature of engagement by most, as one practitioner explained: ‘

there's an independence from the technical work which is critical. If I'm an engineering practice and I'm doing engagement, it's in my interest to drive an engineering outcome that suits my engineering company... it actually changes everything around the strategic approach that might be applied. It changes the questions that they ask, the information that's presented and the way in which they receive information This quote also highlights that the practitioners interviewed did not necessarily identify a need to be independent from the community. On the contrary: Many saw their role as being community advocates. Such a view illustrates the tension of balancing client (and commercial) interests with those of the community. One stated: 'I'm doing my job on behalf of the community and that's hard when you're telling your client that's paying you something that they don't want to hear'. The interpretation of the role of practitioner as community advocate was shared by many but not all. One practitioner employed by the public sector explained:

I've heard a lot of my colleagues say our job is to advocate for the community. I see that as a growing belief or stance from a lot of engagement staff - that they believe that's what their job is... I think when my colleagues are saying we need to make sure that the community really does have a voice and does genuinely get the opportunity to say what they think. My understanding is that is the context in which it's being used but if you talk about being an advocate for the community, it can tilt to a really dangerous territory, you can be almost become part of the community against the project.

Some of the confusion around independence and neutrality may arise from different understandings of the roles of community engagement practitioner and of facilitator, with some practitioners believing them to be the same, while others seeing them as complimentary but separate, with neutrality being more strongly associated with the role of a facilitator (see Chilvers, 2017). 


\section{Public Practitioners vs Consultant Practitioners}

The practitioners interviewed acknowledged differences and challenges in practice arising from whether they were employed by a public institution or were private consultants. Public practitioners reported internal barriers to delivering good processes and some reported concerns for job security. Internal barriers included resistance from other staff at equivalent levels in their organisation, often in those technical professions (town planning; engineering) who were hesitant to have the community involved in their projects. Resistance was also reported at the senior management, executive and decision-maker levels. As one public based practitioner explained:

I think it does take a certain type of engagement practitioner to work in government. It really, really does... It's hard, the things we have to do, the hoops that we have to jump through and the crap that we have to do to get things over the line and hold true to our process as best you can, it's really hard.

Some public practitioners reported that their compliance was linked to their desire for job security, with one explaining, 'With government engagement staff the survival stuff can often take over. You have to appease your master or they'll get someone else to'. The consequence of facing barriers regularly prompted some practitioners to describe how they 'pick their battles':

Sometimes you try and push the boundaries in planning your community engagement but your thing gets shot down so many times that the next time you do a project with the same organisation you basically go for that simple option that you know will get past the decision makers.

Given this example, it would appear the lack of autonomy for public practitioners could be resulting in substandard processes.

When consultant practitioners were asked what tensions they experience they were more reserved in their responses. However, they did speak in general terms of the need to balance the client relationship with their commercial interests. One consultant practitioner succinctly described the conundrum: 'Are they going to pay me for coming up with the wrong answer?'. There was a perception amongst some consultant practitioners that working outside of public institutions was 
easier in many ways. Arguments for this included that the organisations had already recognised the need for engagement and therefore internal resistance was often resolved or minimised. Secondly, without long term ties to the organisation or the community, it can be easier to remain impartial: It's much easier to be objective when you're a consultant and you're just brought in. Here's the project, I want you to go and engage this community on it. And so you go out, you know it's not your project, you're not wedded to it and you don't have any particular allegiance to it. You go and do a good job, you represent the project fairly, you represent the community fairly... I have worked on other projects longer-term and you start to feel a sense of ownership for that project. It is much harder to maintain your objectivity around that project the longer you're with it and the longer you see at evolve.

Interestingly, many practitioners viewed other types of practitioners (private, public, large organisation, small organisation) as more compromised than themselves. For example, and conflicting with the previous quote, one public sector practitioner believed their position allowed them to remain neutral about engagement outcomes.

My perspective is that I'm not here to defend. So it depends on how you see your role I guess. I understand my role as being to develop and deliver opportunities for people to have their say. I guess it depends on where your dollars are coming from. And that's why I work for government because I couldn't work for private industry and try and push a particular perspective.

Some practitioners believed practitioners in large organisations - whether they be large consulting firms or large public institutions - were more likely to be compromised.

If you're an employee of an organisation and you're engaging around a project, you are compromised in that your job is to get this project done for the organisation... Referencing the project over the group is a really tough position that people get put into.

Taken together, these findings suggest that practitioners see their work as challenging at times, but that they favour their own environments over other types.

To date, studies that have looked at public and consultant practitioners have tended to focus on one or the other or both together (Bherer et al., 2017b; Hendriks and Carson, 2008; Lee, 2015; Mazeaud and Nonjon 2017). In 2017, Escobar published research on 'official', or public, based 
practitioners which discussed their unique context and the nature of work which was often defined by internal activism and burnout. Those findings, along with the ones presented here, suggest that public practitioners experience unique challenges which change the nature of their work to a type of 'internal advocate and system navigator', a role that lacks security in an increasingly political environment.

\section{Constraints and Behaviours of Public Institutions}

Whether public or consultant practitioners, the constraints and behaviours of the public institutions which practitioners were employed in or contracted to were viewed as contributing to the tensions they faced.

\section{When a practitioner agrees with a community}

Practitioners reported that there were often instances where the community opposed the decision reached at the conclusion of an engagement process. It was a tension for practitioners when they felt that the community was justified in this response.

Sometimes a decision either has been made or is going to be made that the community might not like and when you're an engagement practitioner out there talking to the community and they're saying, 'I don't want that to happen I think it should be something else'. We might agree with them but we're employed by the organisation and the decision is out of our hands. So we kind of have to say, 'Well sorry that's the way it is'...I guess that puts us in the sticky position in the middle.

Examples like this were raised by both consultant and public practitioners, with them all pragmatically concluding that the reality is that the organisation or project interest prevails over community interest.

\section{When practitioners lack authority}

Within public institutions, the loyalty a practitioner feels to an organisation can also have an impact 
upon the delivery of project, with practitioners expected to 'toe the company line' in what is ultimately a political environment. If the practitioner is not operating with a degree of authority, interaction in the engagement process can be impeded. A practitioner gave this example:

[It's difficult] when a community member asks you a very straightforward question and you want to answer with a very straightforward answer but you can't because your manager is in the room or there is an elected member or there is a board member.

The lack of authority results in practitioners being conflicted over their ability to demonstrate values such as integrity, honesty and openness.

\section{When the engagement is tokenistic}

Tokenistic engagement was understood by practitioners as engagement where the community has very little or no influence over the decision or project. Many practitioners reported being frustrated when working on projects with limited influence available to the community, with some viewing it as the nature of the work and others actively avoiding it. When talking about projects where there was no opportunity for the community to influence the outcome or decision, one public practitioner stated: 'I'm conflicted when I know that the community engagement will not have one iota of influence on the decision'. Another public practitioner described it as: 'practitioners are in a really difficult position ... where they [are] often told go and engage and there's not a hell of a lot to engage on because the decision has already been made'. At a greater extreme, one public practitioner stated: 'They're often put in the position of doing the cover up and that really goes against the grain of the practitioner that's sitting there going: 'This is not genuine engagement and I've been asked to basically lie'. Practitioners spoke of how in some instances organisations chose to engage on smaller aspects of a project, either because the larger decision has already been made (typically by state and/or federal government) or because the commissioning organisation was reluctant to give influence to the community on the larger decisions. 
We're asking the community how big they want the wall to be and what colour they want to paint it and we know that they don't actually want the wall. So we're not consulting with them on the things they care about and are impacted by, we just consulting or engaging on the add-ons that have no value and it's a hard tension to reconcile.

Practitioners also spoke of how the influence available to the community changes as the result of related political, financial and policy decisions. One public practitioner told the story of a large project wherein the community had been informed that there would be an opportunity to influence the outcome. Yet not long after making this message public, the adjacent funding agency declared that they did not want to undertake any community engagement. The practitioner reported that they advocated internally for some community involvement, motivated by good practice and attempting to meet the expectation their organisation had already raised with the community. They conceded that any involvement was likely to be minimal. Additionally, practitioners spoke of being 'rushed' in undertaking engagement, with one public practitioner stating: 'I think because government is such a focal point for the community... We have to quickly do something. So the speed in which it moves and the decision-making is a reaction to community. They want to engage but they make it impossible with the speed in which they act'.

\section{When the bureaucracy and the decision-makers aren't aligned}

While the decision to undertake community engagement processes in public institutions is often dictated by legislation (see, for example, Christensen 2018b) in many instances it was considered good practice. Regardless of whether the process is mandated or not, participants in this study observed that there could be differences of opinion between the public servants who design and deliver or contract the engagement process, and the elected representatives in how the engagement should be undertaken. Tensions were viewed as arising for the practitioner when these two parties are not in alignment. One consultant practitioner spoke of how the staff in organisations who contracted them were eager to run good engagement processes, with it then becoming apparent that 
the elected representatives are either reluctant or in opposition to engagement. One participant gave the example of a mayor who dissuaded other councillors to vote against a proposal to appease a close friend, despite an extensive engagement process.

\section{When decision-makers are not fully committed or understanding of the process}

Community engagement processes are designed to consider community views and give the community (varying levels of) influence over decisions. The processes are often different to more traditional decision-making processes and in some instances they require the decision-maker to hand over some of their power. Some practitioners interviewed spoke of how decision-makers are keen to 'be seen' to be more participatory by their communities, but struggled with the reality of participatory processes and handing over a degree of decision-making power. Practitioners reported that in these instances they were required to support the decision-makers and build their capacity, lest the engagement processes were put at risk. Speaking about an organisation that undertook a more participatory process than they would usually undertake, one practitioner stated:

It was a very disempowering process for some of the older [decision-makers] who really struggled and we had to work very hard to try and keep these people supportive of the process... There was a whole extra job on the sideline of keeping particularly three or four older members in close to us because that could have derailed the process. On the other hand we had ...people who were very dismissive of the organisation and of the [decision-makers] and the quality of the [decision-makers].

In these instances, the practitioner must manage expectations of both parties often in an environment of mutual distrust between decision-makers and community.

\section{When senior public servants and political advisors interfere}

The outcomes of community engagement processes are not known until the engagement process is complete. This uncertainty can make stakeholders anxious. When practitioners were questioned about if there was any interference in engagement processes, many answered it was most likely to 
come from senior and executive public servants and political advisors, rather than decision-makers. For instance: 'There is some interference because the people who are generally reporting to the politicians don't want to give a bad account of their project so there's a bit of push and shove around what those reports look like'. Another practitioner gave a more specific example of when an idea suggested by a participant was in opposition to government policy. The practitioner was told that the recommendation reached by the engagement process would be removed by a senior government advisor, upon which they informed the advisor, 'If this happens I've got no credibility and I think I'd have to walk out... Because you've actually just walked away from the process. Government doesn't have to do the things they said [rather] it's an idea to consider'. These examples hint at senior civil servants' desire to manage risk and reputation, which result in the community engagement practitioner defending the process and the involvement of the community.

When public institutions are unsure how to balance community and expert views Practitioners work alongside subject matter experts, such as land use planners, engineers, policy specialists and scientists. While participants in this study frequently reported experiencing a tension, and needing to be independent from these experts, as discussed earlier, they also expressed the view that public institutions were often unsure about how to balance the needs of communities and experts. Experiences seemed to vary, with some organisations interpreting the objective of community engagement as incorporating as much feedback as possible, relevant or not, from the community, with some going as far to create a Key Performance Indicator to report on this. Other participants were protective of the experts, as one stated:

the challenge is still around the expert... The reflection is, 'It's the science!' For me the tension that we try to hold is absolutely recognising and valuing that role [of the expert] but let's not forget about the role and the value community have and the expertise they have.

Presumably some aspects of projects or decisions are best left to experts, some best left to community, and others a negotiation, but in the absence of clear direction, community engagement 
practitioners are left to mediate.

\section{When the engagement is finished and the outcomes need to be implemented}

Some practitioners spoke about how they were often concerned with how organisations implemented the outcomes of the engagement they facilitated. One consultant practitioner articulated this as having to 'know how to implement it internally so it continues to have a life'. They described how getting to the decision is often the easy part, compared with it then being implemented, an aspect which they feel is often out of their control as a practitioner, more so if they are a consultant. Another consultant practitioner expressed frustration in instances when organisation does not act on the outcomes:

...the decision-makers say, 'No, we're not going to do that' or 'Our priorities have changed and we might look at it in five year's time if we've got budget'... [and we want to respond]

A public practitioner expressed the same concern and added that often they are unable to communicate to the community the reason why a particular project has stopped. They did not indicate if this was because they themselves were unsure of the reasons or if they had been directed to not inform the community the reasons for the project halting. The practitioners tended to frame their frustration on behalf of the communities who participated in such processes but it was also apparent that it was frustrating from the perspective of a practitioner.

\section{Tensions from the Community}

The vast majority of tensions identified by the practitioners interviewed related, as shown above, to the role of the practitioner and the institutions they are working for and on behalf of. Tensions arising from the community and the actual process of facilitating engagement with the community, were given only a cursory mention by most, such as 'well there are lots [of tensions] when you're in the detail of a process, but...', or as a root of a tension which is mismanaged, causing tension for the practitioner. For example, one interviewee noted that there is a 'heightened sense of expectation from 
the public to know things quickly' and continued to explain how in the face of this demand public institutions are too risk averse to be able to respond quickly and honestly. While the community was not identified as a major source of tensions by those interviewed, the cursory mentions suggest that the work with community is perceived as justifiably difficult and expected, whereas the other tensions presented were not.

\section{Managing Tensions}

In probing how participants sought to manage these tensions, this study found that the effectiveness of a practitioner and the processes they deliver were dependent on how they reconciled or manage tensions such as those described. Three main strategies were identified amongst the practitioners interviewed. First, was the strategy of avoidance. Several consultant practitioners mentioned that they avoided working with some client organisations in instances where they thought, or knew from experience, that the work would be very difficult or not in alignment with their principles or the type of work they were building their profile on: 'I choose my clients pretty carefully'. The preferred tactic in these instances was to claim they were unavailable. Notably, public practitioners are often unable to choose which work to do. Second, was the strategy of prevention, which generally consisted of communicating and building capacity at the beginning on what to expect and what was required by the organisation as well as the community, as one practitioner succinctly states, 'it's always about making sure that our processes are bulletproof, so when they are attacked, we can defend them'. How practitioners signalled what to expect and what was required included structured approaches such as agenda items at project commencement meetings about how to work together, the questioning of project teams, regular communication about what to expect, and including the IAP2 Core Values and Code of Ethics as part of tender documentation. Third, was the strategy of managing the tension. Many of those interviewed spoke of the having honest but difficult conversations with the sponsor of the engagement. Practitioners spoke of how issues with 
community expectations and organisational expectations were very common. In addition, other strategies identified by practitioners interviewed included partnering with a third party who then acts as an intermediary. Also included was the tactic of deferring to participants about the way forward and escalating issues to more senior staff.

Consultant practitioners spoke of how if these strategies were unsuccessful they would consider terminating their involvement as they spoke about being prepared or 'willing to walk away'. In the examples given, practitioners' frustrations were directed towards the organisation rather than the community, typically in situations where the organisation was not taking advice on process from them, or where the organisation became reluctant to involve or give influence to the community despite earlier promises to do so, or where the organisation was not making information or outcomes publically available. With walking away being a less viable option for public practitioners, they instead described how they 'make the best' of it. Arguably, this developmental approach to improving engagement practice is a just response to the contextual complexities described earlier.

\section{Principles}

Principles were identified as serving as a guide to many practitioners for how to recognise when their process or practice is at risk of being compromised. Approximately half of those interviewed referred to the importance of principles or values in their practice and how they have served as a foundation of their practice, as one practitioner stated: 'How do you manage it [the tensions]? You come back to principles. That's what I find I constantly do is go to the principle... What would be the best ethical choice if transparency is our goal?'. Integrity was explicitly mentioned by some practitioners, as one explained: 'I think engagement is very much a values-based science/profession. And really that's integrity. I think it's something that I see with a lot of practitioners. Integrity of process, integrity of who they are, integrity around access and inclusion and what's right fundamentally right for people'. Adherence to these principles not only assists practitioners in recognising the limits of where they 
are willing to go with their practice but, as one practitioner described, also allows them to manage the tensions. They explained: 'We've gotten to a stage where we feel we can say... that would go against our principles... This doesn't sit well, we can't possibly go forward. More often and not you're able to negotiate a way through that. Give them [the client] a shock and then they go, 'ok, now that make sense.'

\section{Position Counts}

The use of the phrase 'gotten to a stage' in the last quote assists in making the final point of how practitioners manage tensions and that is - position counts. How experienced the practitioner is, how confident the practitioner is, their position in the hierarchy, their relationship with senior leaders and decision makers and even the profile and understanding of community engagement in the organisation all impact how practitioners perceive and manage tensions. Many of the practitioners interviewed acknowledged that with more experience they have felt more comfortable 'pushing back' against the stated wishes of their clients, although many prefaced those comments with a need to 'pick your battles'. Several practitioners stated that the more complex and challenging processes provided the greatest learning. Those interviewed for this study were senior practitioners; therefore it is important to note that less experienced practitioners may perceive and manage tensions differently and may be less confident and secure in challenging senior leaders and decision-makers to ensure certain standards in practice. As one practitioner explained:

I'm old enough now and wise enough now to know whether it's right or not... I feel confident that I can

challenge now because I can round out my reasons why I'm challenging them now. With 16 years of facing the same battles I'm confident enough now that I can turn around the senior managers ... when I was just starting I certainly wouldn't have that confidence to challenge them on things.

This situation may have further consequences for quality and effectiveness of engagement processes.

\section{Concluding Discussion}


Returning to the literature, the two themes of how practitioners negotiate the balance between commercial and community interest and the constraints of public institutions are present here. With respect to the tension surrounding commercialisation, previous research is divided with some concluding that practitioners were evenly balanced between democratic ideals and the market (Hendriks and Carson 2008; Cooper and Smith 2012) and others stating they were considerably more compromised (Lee 2014; 2015; 2017). These findings suggest the truth is somewhere in between with the reality likely to be considerably more nuanced, for it is not a case of whether practitioners are driven by commercial or democratic ideals but by how they are perceived by their clients, employers and communities, and consequently how they position themselves. In respect to the challenges faced when working in and with public institutions, the findings that suggest public institutions may be (unintentionally) hindering democratic ideals (Cooper and Smith 2012, Chilvers 2017; Lewanski and Revazzi 2017) are mirrored here. Also mirrored are Escobar's (2017) findings on the additional work of public practitioners. These findings differ, and make their contribution, is in: the greater exploration of the commercial and community interests balance and the tensions practitioners face as a result of the constraints and behaviours of public institutions. Also, the article discusses the ways that practitioner's mange these tensions - an important consideration given the important role they play in protecting the democratic integrity of the processes they design and deliver.

As for the future, increasing professionalisation is expected to occur, bringing with it additional tensions for practitioners to manage. From a theory point of view, the parallels in findings with other studies indicate that a comparative study may be useful along with greater exploration of exactly how practitioners affect democratic process. And from a practice point of view, the field may want to consider the important role that principles could play in improving standards and providing guidance (also noted by Cooper and Smith, 2012). 


\section{References}

Aulich, C. (2009) 'From Citizen Participation to Participatory Governance in Australian Local Government', Commonwealth Journal of Local Governance, 2: 44-60.

Baiocchi, G. and E. Ganuza. (2017) Popular Democracy: The Paradox of Participation. Stanford, California: Stanford University Press.

Bherer, L.Fernández-Martínez, J. L., Espín, P. G., \& Sánchez, M. J. (2016). The promise for democratic deepening: the effects of participatory processes in the interaction between civil society and local governments. Journal of Civil Society, 12(3), 344-363.

Bherer, L., Gauthier, M., \& Simard, L. (2017a). The Professionalization of Public Participation. New York: Routledge.

Bherer, L., M. Gauthier and L. Simard. (2017b) 'Who's the Client? The Sponsor, Citizens, or the Participatory Process? Tensions in the Quebec (Canada) Public Participation Field', pp. 87-114 in L. Bherer, M. Gauthier and L. Simard (eds) The Professionalisation of Public Participation. New York: Routledge.

Bua, A. and O. Escobar. (2018) 'Participatory-deliberative processes and public policy agendas: lessons for policy and practice', Policy Design and Practice 1(2): 1-15.

Christensen, H.E. (2018a) 'Community Engagement and Professionalization: Emerging Tensions', Research Issues in Ethical Organisations 20:117-133.

Christensen, H.E. (2018b) 'Prescribing, aspiring, empowering and hedging: how Australia's state governments legislate community engagement at the local government level' Commonwealth Journal of Local Governance 21: XX-XX

Chilvers, J. (2017) 'Expertise, Professionalization, and Reflexivity in Mediating Public Participation: Perspectives from STS and British Science and Democracy', pp. 115-138 in L. Bherer, M. Gauthier and L. Simard (eds) The Professionalisation of Public Participation. New York: Routledge.

Cooper, E. and G. Smith. (2012) 'Organizing Deliberation: The Perspectives of Professional Participation Practitioners in Britain and Germany', Journal of Public Deliberation 8: 1-39.

Escobar, O. (2017) 'Making it official: Participation professionals and the challenge of institutionalizing deliberative democracy', pp. 151-174 in L. Bherer, M. Gauthier and L. Simard (eds) The Professionalisation of Public Participation. New York: Routledge.

Fawcett, B. and M. Hanlon. (2009) "The "return to community": Challenges to human service professionals', Journal of Sociology 45(4): 433-444.

Freidson, E. (1989) 'Theory and the Professions', Indiana Law Journal 64(3): 423-432.

Fung, A. (2015) 'Putting the Public Back into Governance: The Challenges of Citizen Participation and Its Future', Public Administration Review 75(4): 513-522.

Gardner, H. E., M. Csikszentmihalyi and W. Damon. (2001) Good Work: When excellence and 
ethics meet. New York: Basic Books.

Glaser, B. G. And A.L. Strauss. (1967) The Discovery of Grounded Theory; Strategies for Qualitative Research. Chicago: Aldine.

Glennie, M., M. O’Donnell, J. Benson and M. Brown. (2018) 'Work as a government "scientist": Professional status security during organisational change and downsizing', Journal of Sociology.

Grant, B. and J. Drew. (2017) Local Government in Australia: History, Theory and Public Policy. Singapore: Springer.

Hendriks, C. M. and L. Carson. (2008)' Can the market help the forum? Negotiating the commercialization of deliberative democracy', Policy Sciences 41(4): 293-313.

Lee, C. W. (2014) 'Walking the Talk: The Performance of Authenticity in Public Engagement Work', The Sociological Quarterly 55(3): 493-513.

Lee, C. W. (2015) Do-It-Yourself Democracy: The Rise of the Public Engagement Industry. New York: Oxford University Press.

Lee, C. W. (2017) 'Public Participation Professionals in the US: Confronting Challenges of Equity and Empowerment', pp. 75-96 in L. Bherer, M. Gauthier and L. Simard (eds) The Professionalisation of Public Participation. New York: Routledge.

Lewanski, R. and S. Ravazzi. (2017) 'Innovating Public Participation: The Role of PPPs and Institutions in Italy', pp. 17-39 in L. Bherer, M. Gauthier and L. Simard (eds) The Professionalisation of Public Participation. New York: Routledge.

Lewis, J. M., T. Marjoribanks and M. Pirotta. (2003) 'Changing professions: General Practitioners' perceptions of autonomy of the frontline' Journal of Sociology 39(1): 44-61.

Lowndes, V., Pratchett, L., \& Stoker, G. (2001) 'Trends in Public Participation: Part 1 - Local Government Perspectives', Public Administration 79(1): 205-222.

Mansbridge, J., J. Hartz-Karp, M. Amengual and J. Gastil. (2006) 'Norms of Deliberation: An Inductive Study', Journal of Public Deliberation 2(1): 1-47.

Mazeaud, A., \& Nonjon, M. (2017) 'The Participatory Democracy Market in France: Between Standardization and Fragmentation', pp. 40-64 in L. Bherer, M. Gauthier and L. Simard (eds) The Professionalisation of Public Participation. New York: Routledge.

Michels, A., \& De Graaf, L. (2010) 'Examining Citizen Participation: Local Participatory Policy Making and Democracy', Local Government Studies 36(4): 477-491.

Moore, A. (2012) 'Following from the front: theorizing deliberative facilitation', Critical Policy Studies 6(2): 146-162.

Moore, M. (1995). Creating Public Value: Strategic Management for the Public Sector. Harvard: Harvard University Press. 
Nabatchi, T. and L.B. Amsler. (2014) 'Direct Public Engagement in Local Government', American Review of Public Administration 44(4): 63S - 88S.

Nabatchi, T. and M. Leighninger. (2015) Public Participation for 21st Century Democracy. Hoboken, New Jersey: John Wiley \& Sons.

Pateman, C. (2012) 'Participatory Democracy Revisited', Perspectives on Politics 10(1): 7-19.

Polletta, F. (2016) 'Public Deliberation and Political Contention', pp. 222-246 in C.W. Lee, M. McQuarrie and E. T. Walker (eds) Democratizing Inequalities: Dilemmas of the New Public Participation. New York: New York University Press.

Sawyer, A.M., D. Green, A. Moran, and J. Brett. (2009) 'Should the nurse change the light globe?: Human service professionals managing risk on the frontline', Journal of Sociology 45(4): 361-381.

Spada, P. and J.R. Vreeland. (2013) 'Who Moderates the Moderators? The Effect of Non-neutral Moderators in Deliberative Decision Making', Journal of Public Deliberation 9(2): 1-31.

Wampler, B. (2010) Participatory Budgeting in Brazil: Contestation, Cooperation, and Accountability. Pennsylvania: Penn State Press.

Wang, X. (2001) 'Assessing Public Participation in U.S. Cities', Public Performance and Management Review 24(4): 322-336. 
Appendix - Interviewee Details

\begin{tabular}{|c|c|c|c|c|}
\hline No. & Gender & Sector & Position & $\begin{array}{l}\text { Years' } \\
\text { Experience }\end{array}$ \\
\hline 1 & Male & State Government & Senior Staff/Middle Management & 16 years \\
\hline 2 & Female & Private consultant & Lead Medium/Large Firm & 20 years \\
\hline 3 & Female & Private consultant & Lead Medium/Large Firm & 18 years \\
\hline 4 & Female & Private consultant & Solo/Lead Small Firm & 19 years \\
\hline 5 & Female & State Government & Senior Management/Executive & 21 years \\
\hline 6 & Male & $\begin{array}{l}\text { Private consultant } \\
\text { (significant public } \\
\text { sector background) }\end{array}$ & Senior Management/Executive & \\
\hline 7 & Female & $\begin{array}{l}\text { Private (significant } \\
\text { public sector } \\
\text { background) }\end{array}$ & Solo/Lead Small Firm & 20 years \\
\hline 8 & Male & Local Government & Senior Staff/Middle Management & 10 years \\
\hline 9 & Female & State Government & Senior Management/Executive & $20-25$ years \\
\hline 10 & Male & Private consultant & Solo/Lead Small Firm & 18 years \\
\hline 11 & Female & Private consultant & Solo/Lead Small Firm & 15 years \\
\hline 12 & Female & Local Government & Senior Management/Executive & 20 years \\
\hline 13 & Female & Local Government & Senior Staff/Middle Management & 10 years \\
\hline 14 & Female & State Government & Senior Management/Executive & 20 years \\
\hline 15 & Female & Local Government & Senior Staff/Middle Management & 14 years \\
\hline 16 & Female & $\begin{array}{l}\text { Private (significant } \\
\text { public sector } \\
\text { background) }\end{array}$ & Solo/Lead Small Firm & 28 years \\
\hline 17 & Male & Private consultant & Solo/Lead Small Firm & 22 years \\
\hline 18 & Female & Private consultant & Solo/Lead Small Firm & 20 years \\
\hline 19 & Female & $\begin{array}{l}\text { Private (significant } \\
\text { public sector } \\
\text { background) }\end{array}$ & Solo/Lead Small Firm & 25 years \\
\hline 20 & Female & Private consultant & Solo/Lead Small Firm & 15 years \\
\hline
\end{tabular}

